\title{
Languishing but Not Giving Up: Suggesting A Surrender-Struggle Continuum as the Missing Piece of The Mental Health Puzzle
}

\author{
Per Eisele* \\ Associate professor, Department of Psychology, Mid Sweden University, Sweden
}

\section{Article Info}

\section{Article Notes}

Received: July 15, 2020

Accepted: September 25, 2020

\section{*Correspondence:}

Dr. Per Eisele, Associate professor, Department of Psychology, Mid Sweden University, Sweden;

Email:Per.eisele@gmail.com.

C 2020 Eisele P. This article is distributed under the terms of the Creative Commons Attribution 4.0 International License.

\section{Keywords:}

Emotional well-being

Psychological well-being

Social well-being

Mental health

\section{Abstract}

Background: The mental health continuum was created for the purpose of measuring mental health with several different wellbeing items.

Aims: The aim of the present study was to investigate the mental health continuum together with a new struggle continuum scale. With languishing and flourishing at the ends of a vertical scale and surrendering and struggling at the ends of a horizontal scale a quadratic model is suggested. Four factors can be distinguished at the corners of the square, depressed, anxious, content and joyful.

Methods: The sample $(\mathrm{N}=294)$ consisted of 174 women with a mean age of 40.48 and 124 men with a mean age of 37.27 year. The mental health continuum scale was used together with a new scale measuring struggling, the tendency to give up easily or keep on fighting.

Results: The model was tested on a normal population and was confirmed. Result of chi-square, correlation and t-test analyses show that the two scales could detect depressed, anxious, content and joyful participants.

Conclusions: The result has implications for the choice between mindfulness and activity-based interventions. Discussion about the result are provided.

\section{Introduction}

The dictionary definition of well-being is a good or satisfactory condition of existence; a state characterized by health, happiness, and prosperity. For a long time, a two-dimensional model of wellbeing has prevailed, the two constructs satisfaction with life and emotional well-being. Satisfaction with life is the cognitive part of well-being ${ }^{1}$ and happiness can be understood as satisfaction with life and emotional well-being put together ${ }^{2}$. That is, researchers working within this paradigm argue that satisfaction with life and emotional well-being together give an adequate description of people's positive mental health. This idea was challenged by Ryff $(1989)^{3}$ who put forward argument that psychological well-being is essential. Ryffs viewpoint highlight the importance of the functional component for the understanding of people's well-being. This functional approach was further developed by Keyes $(1998)^{4}$ who empirically and theoretically showed the importance of social wellbeing.

The Mental Health Continuum-Short Form (MHC-SF) ${ }^{5}$ is a selfreported scale to measure emotional, psychological and social wellbeing. The MHC includes the three core components of the World Health Organization's definition of mental health and have been further validated in several studies ${ }^{6}$. 


\section{Well-being}

Measurements of psychological comfort describes the functional aspect of good life and is thereby contrasted to subjective well-being ${ }^{3}$. A model of psychological well-being with six dimensions was suggested by Ryff and Keyes $(1995)^{7}$. These dimensions are autonomy, environmental mastery, personal growth, positive relations, purpose in life, and self-acceptance. These dimensions have been included in several studies. To mention a few, cognitive behavioral stress management increased environmental mastery and self-acceptance ${ }^{8}$. Purpose in life was a mediator between hope attitude and well-being 9 . In a study by Reis, Sheldon, Gable, Roscoe and Ryan (2000) ${ }^{10}$ autonomy was associated with emotional well-being.

Emotional wellbeing is about the feeling of having been rejoiced and interested in life. The personally functional component of well-being is about liking most aspects of one's personality and wanting and being able to grow to be a better person. Being able to handle responsibilities and thought and expressed one's own ideas as well as having intimate relationships with other people and a purpose in life.

The mental health continuum ${ }^{4}$ was an important contribution to well-being research since it included social well-being. Being a part of a community and feel that you add something important to the society is important for people's health. The belief that our society gets better for people and that humans are in basically good should be associated with well-being through feelings of hope. Whether the society people live in make sense or not and if they feel they understand how their society works.

\section{The Origin of the Struggling Scale}

The surrendering-struggling continuum has been inspired by several concepts like optimism, goalorientation, locus of control and self-efficacy. People strive or struggle to a different degree. When things go against them many feel little hope and might get stuck in a state of hopelessness. In a study by Aghababaei, Sohrabi, Eskandari, Borjali, Farrokhi and Chen $(2016)^{9}$ it was found that both religiosity and belief in science were positively related to subjective well-being. These relationships were mediated by hope and purpose in life. Some people seem not be depressed no matter what misfortune hit them. They keep on struggling without losing hope.

Optimism ${ }^{11}$ is about expecting the best and thinking things will go well. It has been known to affect health and wellbeing ${ }^{12}$. Optimism can be conceptualized as confidence about pertaining good life ${ }^{13}$. That is, optimism is a general and not context-specific concept. An optimist is more likely to be persistent even when facing difficult challenges. Some people seem not to get depressed no matter what misfortune hit them. They keep on struggling.
People that score high on generalized self-efficacy ${ }^{14}$ believe they have the resources needed to achieve most of the goals they set for themselves. The feeling of being able to accomplish difficult tasks and to obtain outcomes. Self-efficacy affects both health and well-being, believing one can succeed is an important energizer ${ }^{15}$. Both internal and external locus of control can be associated with health behavior. People with internal locus of control might be good at problem-focused coping since they keep on working to achieve goals ${ }^{16}$. While people with external locus of control in general find it easier to seek support and help. For a recent review, see for example Cheng, Cheung and Lo $(2016)^{17}$.

Goal orientation ${ }^{18,19}$ is about seeking out challenging work. People that score high on goal orientation prefer to work on tasks that help them learn new things. They tend to seek out opportunities to learn new things and tries hard to improve on past performance. People low in goal orientation can be seen as using avoidance strategies, for example avoiding risks. Goal orientation is a mindset towards the achievement of work-related goals, and it has been found to be related to occupational well-being. Adriaenssens, Gucht and Maes (2015) ${ }^{20}$ explored a fourdimensional model of goal orientation and found that goal orientation explained $14 \%$ of the variance in burnout. The performance-avoidance goal orientation was strongly related to an increase in burnout.

Some strugglers feel anxiety, and some don't. Feeling some kind of "life joy" during circumstances when most people would feel depressed. This struggling capacity is the background for the new suggested scale, the surrenderingstruggling questionnaire. Surrendering easily while scoring high on well-being constitute a relaxed fulfillment that can be labeled content. While surrendering accompanied with low well-being form the feeling of being depressed.

The struggle scale was inspired by several measurements, including optimism, goal orientation, locus of control and self-efficacy. The purpose of the study was to test the new struggling scale together with the three wellbeing measures that constitute the MHC-SF. The main question concern whether people in the four corners of the square (Figure 1) could be detected. That is, anxious (low wellbeing and high struggling), depressed (low wellbeing, low struggling), content (high well-being, low struggling), and joyful (high wellbeing and high struggling).

To clarify, the aim of the present study was to test a model with a new scale together with MHC_SF. A model is proposed that has the potential of improving categorical diagnosis of positive mental health. With languishing and flourishing at the ends of a vertical scale and surrendering and struggling at the ends of a horizontal scale a quadratic model (figure 1 ) is suggested. Four factors can be distinguished at the corners of the square: depressed, anxious, content 


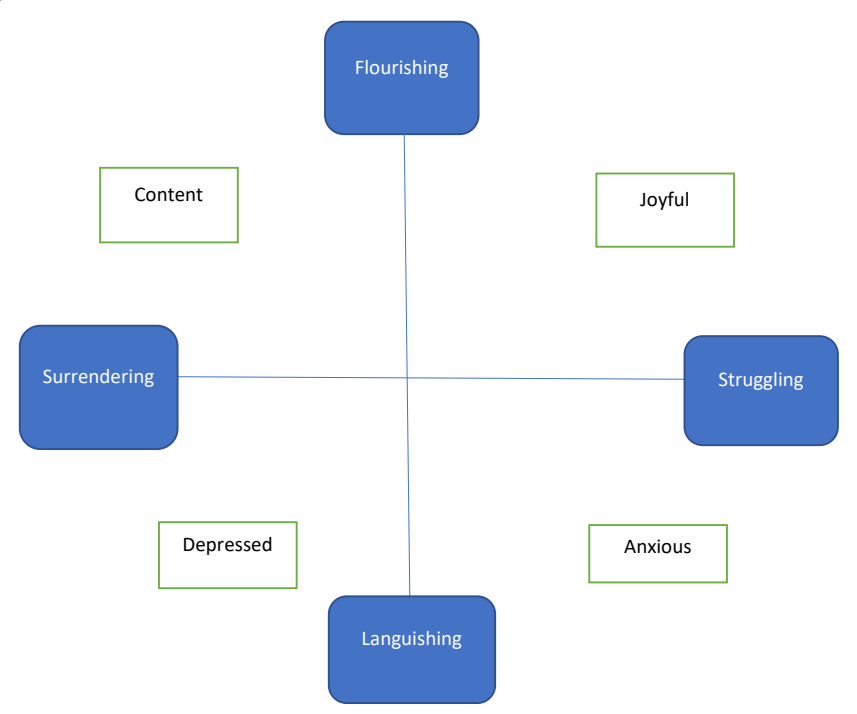

Figure 1. The model with two mental health continuums.

and joyful. Being in a languishing state of mind without striving or struggling constitute the depressed category. Some people however are still struggling despite low selfreported well-being. These kinds of persons seem to keep on no matter what misfortune they come across. They somehow manage to remain optimistic and goal-oriented but if well-being score is low and struggling score high, they will find their life situation filled with anxiety. In the suggested model, these people are categorized as anxious. People scoring high in flourishing have reached a state of fulfillment but there is the difference between layback happiness and 'bouncing in joy happiness'. Strivers or 'strugglers' with high degree of well-being is categorized as joyful while some seem to be relaxed and comfortable and is categorized as content. Thus, the present study suggests a surrender-struggle continuum to accomplish the mental continuum in a quadratic model.

\section{Method}

\section{Participants}

Three hundred volunteered to participate but 6 people withdrawn after they were asked to give consent to fill out the questionnaire. The sample ( $\mathrm{N}=294)$ consisted of 174 women with a mean age of $40.48(\mathrm{SD}=12.66)$ and 124 men with a mean age of 37.27 ( $S D=11.36)$. Thirty-six were unemployed and 160 had work. Three categories about the financial situation, low ( $\mathrm{n}=74)$, middle $(\mathrm{n}=208)$, and high $(\mathrm{n}=12)$.

\section{Measures}

\section{Wellbeing}

For the present study the short version of the Mental Health Continuum (MHC-SF) was used. The current version of the MHC-SF (Keyes et al., 2008) ${ }^{6}$ consist of 14 items, 3 about emotional well-being, 6 about psychological well- being and 5 about social wellbeing. The Likert scale started with 0 (Never) on the left and ended with 5 (Every day) to the right.

\section{Struggling scale}

The following 11 items on a zero (Never) to five (Every day) Likert scale was used in the present study:

If thing goes wrong, I still keep myself busy.

When I am feeling low, I stop trying to achieve the goals I set for myself. $\mathrm{R}$

I will be able to successfully overcome many challenges.

Even when things are tough, I can perform quite well.

When I fail to complete a difficult task, I plan to try harder the next time I work on it.

When I face difficulties, I still try hard to do my best.

I give up easily $\mathrm{R}$

When I have difficulty solving a problem, I try different approaches to see which one will work.

Even when I feel down, I enjoy challenging and difficult tasks.

I prefer to avoid situations if I risk appearing incompetent. $\mathrm{R}$

When I make plans, I keep on trying to make them work.

Please note that the English version of the struggling scale presented here have not been validated, only the Swedish version has been.

Additionally, four visual analog scales where used. The participants estimated their current feelings of being; depressed, anxious, content, and joyful on four corresponding $100 \mathrm{~mm}$ long scales.

\section{Procedure}

Several pilot studies have been conducted prior to the present study to develop the struggling scale. The scale started with 20 items and the current 11-item scale have a satisfactory Cronbach Alpha of .87.

Participants volunteered to take part in the study and all that gave consent was included. An ongoing well-being project using a blog, a Facebook page and a web page was used for initial contact with the participants.

For this study the measurements where sent out by email. The participants were reminded three times until $98 \%$ filled out and returned the measurements. After completion of the data, all participants received a brief description of the purpose of the study and the main result. All participants got the possibility to receive their own personal scores. 
Ethical considerations were taking into account. One benefit of using positive well-being is that the risk of triggering negative feelings regarding the subject matter are much lower compared to e.g. depression inventories. Still, in case any participant felt bad about the items, clinical psychologists were ready to communicate with them. No participant in the present study reported evoked bad feelings.

\section{Result}

\section{Descriptive statistics}

There were no significant gender differences on any dependent variable. There was a significant difference regarding work situation (work/ no work) for mental health $(\mathrm{t}=3.53, \mathrm{df}=146, \mathrm{p}=.001)$ but no difference regarding struggling. All the three well-being measures correlated strongly. The struggling scale correlated to a low degree with psychological well-being and moderately with emotional- and social well-being. Cronbach's Alpha for psychological wellbeing was .91, for emotional wellbeing .94 , for social wellbeing .87 , and for the struggling scale .90 (Table 1.).

The crosstab show that participants fall in all 9 squares created by the $3 \times 3$ quadratic model (chi2 $=11.78, d f=4$, $\mathrm{p}=.019$ ) (Table 2).

\section{Discussion}

The aim of the present study was to investigate the mental health continuum scale (Keyes, 1998) ${ }^{4}$ together with a new struggle scale. It was argued that the quadratic model

Table 1: Means, standard deviations, correlations, and Cronbach's Alpha of the study variables.

\begin{tabular}{|c|c|c|c|c|c|}
\hline & $\begin{array}{c}\text { Means } \\
\text { (SD) }\end{array}$ & 1 & 2 & 3 & 4 \\
\hline Psychological well-being (1) & $\begin{array}{c}2.61 \\
.83\end{array}$ & .95 & & & \\
\hline Emotional well-being (2) & $\begin{array}{c}2.53 \\
.92\end{array}$ & $\begin{array}{c}.89 \\
<.001\end{array}$ & .91 & & \\
\hline Social well-being (3) & $\begin{array}{c}2.54 \\
.95\end{array}$ & $\begin{array}{c}.82 \\
<.001\end{array}$ & $\begin{array}{c}.86 \\
<.001\end{array}$ & .81 & \\
\hline Struggling (4) & $\begin{array}{c}2.99 \\
.79\end{array}$ & $\begin{array}{c}.35 \\
<.001\end{array}$ & $\begin{array}{c}.51 \\
<.001\end{array}$ & $\begin{array}{c}.50 \\
<.001\end{array}$ & .95 \\
\hline
\end{tabular}

\begin{tabular}{|l|c|c|c|c|c|}
\hline & $\begin{array}{c}\text { Means } \\
\text { (SD) }\end{array}$ & $\mathbf{1}$ & $\mathbf{2}$ & $\mathbf{3}$ & $\mathbf{4}$ \\
\hline Psychological well-being (1) & $\begin{array}{c}2.61 \\
.83\end{array}$ & .95 & & & \\
\hline Emotional well-being (2) & 2.53 & .89 & .91 & & \\
\hline Social well-being (3) & .92 & $<.001$ & .91 & & \\
\hline Struggling (4) & 2.54 & .82 & .86 & .81 & \\
\hline & .95 & $<.001$ & $<.001$ & .00 & \\
\hline
\end{tabular}

Note: Whole sample, $\mathrm{N}=294$.
Table 2. Chi-square analyses of the quadratic $3 \times 3$ model.

\begin{tabular}{|c|c|c|c|c|}
\hline & & Mental health & & \\
\hline \multicolumn{2}{|c|}{ Struggling low } & medium & high & total \\
\hline low & $\begin{array}{l}\text { Depressed } \\
\qquad \mathrm{N}=15\end{array}$ & $N=9$ & $\begin{array}{c}\text { Content } \\
\mathrm{N}=13\end{array}$ & $N=37$ \\
\hline medium & $\mathrm{N}=20$ & $N=33$ & $\mathrm{~N}=41$ & $\mathrm{~N}=94$ \\
\hline high & $\begin{array}{c}\text { Anxious } \\
\mathrm{N}=49\end{array}$ & $N=70$ & $\begin{array}{l}\text { Joyful } \\
N=44\end{array}$ & $N=163$ \\
\hline total & $\mathrm{N}=84$ & $\mathrm{~N}=112$ & $\mathrm{~N}=98$ & $N=294$ \\
\hline
\end{tabular}

created by the two scales would be helpful in distinguishing anxious feelings from depressed feelings. People reporting low scores on well-being scales but high on struggling was labeled anxious, while people reporting low scores on wellbeing scales and low on struggling was labeled depressed. Correspondingly, the difference between being content or joyful might increase our understanding of well-being.

Result of chi-square analysis show that the two scales together could detect depressed, anxious, content and joyful participants. The result matters since interventions should be more efficient if it is possible to set goals differently according personal needs. Anxious people might benefit more from mindfulness-based interventions and depressed people more from activity-based interventions.

\section{Conclusion}

Mindfulness based interventions have been used for both depressed and anxious people and to a great amount in stress reduction ${ }^{21}$. There is some evidence that mindfulness cognitive behavioral therapy may not be diagnosis-specific, but, instead, may address processes that occur in multiple disorders by changing a range of emotional and evaluative dimensions that underlie general aspects of wellbeing ${ }^{22}$. Behavioral activation together with mindfulness-based therapy have been confirmed effective for both anxiety and depression ${ }^{23}$. However, to my knowledge no study has compared the two different interventions or treatments for depressed and anxious people respectively. Although there is no empirical evidence that mindfulness-based interventions are better suited for anxiety than for depression it should be important to investigate in future.

The data gave support to the model, but the study have two clear limitations, the sample size and the sample procedure. The small sample size makes it difficult to generalize the result and people already interesting in enhancing well-being might not be representative.

The benefit of measure depression and anxiety with positive scales is that a depression and/or anxiety inventory might trigger negative thoughts or feelings. But still, in future studies, with larger sample, the quadratic model suggested here should be compared with data from Beck Depression Inventory-II (BDI-II; Beck, Steer, \& Brown, $1996)^{24}$ and Beck Anxiety Inventory (BAI; Beck \& Steer, 1993) ${ }^{25}$. 
Despite the shortcomings the study is an important contribution to the understanding of well-being and mental health. The result has implications for the development of mental health measurements as well as for interventions to enhance public mental health and well-being.

\section{References}

1. Diener ED, Emmons RA, Larsen RJ, et al. The satisfaction with life scale. Journal of personality assessment. 1985; 49(1): 71-75.

2. Diener E. Subjective well-being: The science of happiness and a proposal for a national index. American psychologist. 2000; 55(1): 34 .

3. Ryff CD. Happiness is everything, or is it? Explorations on the meaning of psychological well-being. Journal of personality and social psychology. 1989; 57(6): 1069.

4. Keyes CL. Social well-being. Social psychology quarterly. 1998; 121140 .

5. Keyes CL. The mental health continuum: From languishing to flourishing in life. Journal of health and social behavior. 2002; 207 222.

6. Keyes CL, Wissing M, Potgieter JP, et al. Evaluation of the mental health continuum-short form (MHC-SF) in Setswanaspeaking South Africans. Clinical Psychology and Psychotherapy. 2008; 15(3): 181.

7. Ryff CD, Keyes CLM. The structure of psychological well-being revisited. Journal of personality and social psychology. 1995; 69(4): 719.

8. Fard AD, Mojtabaei M. The Effect of Cognitive Behavioral Stress Management and Psychological Well-Being and Adherence to Treatment In Patients with Coronary Heart Disease (Chd). International Journal of Humanities and Cultural Studies. 2016; 2356-5926, 1(1): 271-284.

9. Aghababaei N, Sohrabi F, Eskandari H, et al. Predicting subjective well-being by religious and scientific attitudes with hope, purpose in life, and death anxiety as mediators. Personality and Individual Differences. 2016; 90: 93-98.

10. Reis HT, Sheldon KM, Gable SL, et al. Daily well-being: The role of autonomy, competence, and relatedness. Personality and social psychology bulletin. 2000; 26(4): 419-435.

11. Scheier MF, Carver CS, Bridges MW. Distinguishing optimism from neuroticism (and trait anxiety, self-mastery, and selfesteem): A reevaluation of the Life Orientation Test. Journal of Personality and Social Psychology. 1994; 67: 1063-1078.
12. Wrosch C, Jobin J, Scheier MF. Do the emotional benefits of optimism vary across older adulthood? A life span perspective. Journal of Personality. 2016; 84: 23-39.

13. Scheier MF, Carver CS, Bridges MW. Optimism, pessimism, and psychological well-being. In E. C. Chang (Ed.), Optimism and pessimism: Implications for theory, research, and practice. Washington, DC: American Psychological Association. 2001; 189-216.

14. Chen G, Gully SM, Eden D. General self-efficacy and self-esteem: Toward theoretical and empirical distinction between correlated selfevaluations. Journal of organizational Behavior. 2004; 25(3): 375-395.

15. Chenoweth L, Stein-Parbury J, White D, et al. Coaching in self-efficacy improves care responses, health and well-being in dementia carers: a pre/post-test/follow-up study. BMC health services research. 2016; 16(1): 1 .

16. Levenson H. Differentiating among internality, powerful others, and chance. In H. M. Lefcourt (Ed.), Research with the locus of control construct (Vol. 1, pp. 15-63). New York: Academic Press. 1981.

17. Cheng C, Cheung MWL, Lo BC. Relationship of health locus of control with specific health behaviours and global health appraisal: a meta-analysis and effects of moderators. Health Psychology Review. 2016; 1-19.

18. Button SB, Mathieu JE, Zajac DM. Goal orientation in organizational research: A conceptual and empirical foundation. Organizational behavior and human decision processes. 1996; 67(1): 26-48.

19. VandeWalle D. Development and validation of a work domain goal orientation instrument. Educational and Psychological Measurement. 1997; 57(6): 995-1015.

20. Adriaenssens J, Gucht VD, Maes S. Association of goal orientation with work engagement and burnout in emergency nurses. Journal of occupational health. 2015; 57: 151-60.

21. Grossman P, Niemann L, Schmidt S., et al. Mindfulness-based stress reduction and health benefits: A meta-analysis. Journal of psychosomatic research. 2004; 57(1): 35-43.

22. Hofmann SG, Sawyer AT, Witt AA, et al. The effect of mindfulnessbased therapy on anxiety and depression: A meta-analytic review. Journal of consulting and clinical psychology. 2010; 78(2): 169.

23. McIndoo CC, File AA, Preddy T, et al. Mindfulness-based therapy and behavioral activation: A randomized controlled trial with depressed college students. Behaviour research and therapy. 2016; 77: 118-128.

24. Beck AT, Steer RA, Brown GK. Manual for the Beck Depression Inventory-II. San Antonio, TX: Psychological Corporation. 1996.

25. Beck AT, Steer RA. Beck Anxiety Inventory: Manual (2nd edition). San Antonio, TX: The Psychiatric Corporation. 1993. 